\title{
Care pathways for patients with COPD in Italy
}

\author{
Stefano Calabro \\ Pulmonology Unit, Department of Medicine, "S. Bas- \\ siano” Hospital, Bassano del Grappa, Italy
}

\author{
Address for correspondence: \\ Stefano Calabro, MD \\ Pulmonology Unit, Department of Medicine \\ "S. Bassiano" Hospital \\ Via dei Lotti, 40 \\ 36061 Bassano del Grappa, (VI), Italy \\ Phone +39 0424 888515; Fax +39 0424888827 \\ E-mail: stefano.calabro@aslbassano.it
}

\section{Summary}

Chronic health conditions are rapidly increasing. Chronic obstructive pulmonary disease (COPD) is one of the most common lung diseases.

COPD has considerable impact on the quality of life of the patient, involving long-term medical care and frequent hospital admissions for treatment of exacerbations.

The current acute care model for COPD is, in general, insufficient for optimal management of the disease.

The optimal care of the patient with COPD requires an individualized, patient-centered approach that recognizes and treats all aspects of the disease. The optimal treatment for COPD patients must address symptoms and disability from the respiratory disease and from its extra-pulmonary conditions, adhering to principles of the chronic care model and integrated care. In Italy the National Health System promotes strategies of integrated care for controlling COPD.

It is essential to ensure coordinate health policies, both at local and national level. Only integrating adequate health policies with an optimal cooperation among general practitioners, chest physicians and other specialists whenever required, may assure the best management of the COPD.

KEY WORDS: chronic obstructive pulmonary disease, clinical pathway, continuity of care, integrated care.

\section{Chronic obstructive pulmonary disease in Italy}

Chronic respiratory diseases are a group of pathological conditions that are still insufficiently prevented, under-treated and underdiagnosed (1).

Among the chronic respiratory diseases, obstructive pulmonary disease is a public health problem (2). In Europe, the estimated prevalence of chronic obstructive pulmonary disease (COPD) is around 4$7 \%$, with male gender and older age groups being the most affected (3).

The actual prevalence of this
In order to develop a comprehensive approach for surveillance, diagnosis, prevention and control of chronic respiratory diseases, the Ministry of Health has joined GARD, an alliance promoted by the World Health Organization. disease in the same population may vary depending on the criteria used to identify it (Figure 1), namely, reported respiratory symptoms, medical diagnosis, or lung function $(4,5)$.

According to a recent Italian study, COPD affects approximately $3 \%$ of the population with prevalence rates increasing in older age and male gender groups. It reaches $20 \%$ of males over 60 years old (6).

During the years, Italy has carefully considered the epidemiological and social impact of respiratory diseases. In the National Health Plan 2006-2008, the epidemiological and social impact of respiratory diseases was set as one of the main health targets, along with cancer, cardiovascular diseases and diabetes (7). In the National Prevention Plan 2010-2012, chronic respiratory diseases were included in the priority areas of intervention (8).

Further, in order to develop a comprehensive approach for surveillance, diagnosis, prevention and control of chronic respiratory diseases, the Ministry of Health has joined GARD (International Global Alliance Against Chronic Respiratory disease), an alliance promoted by the World Health Organization (WHO). GARD includes organizations, institutions and agencies working for the common aim of improving the overall respiratory health (9), and several organizations adhere to GARD Italy (10).

These initiatives have led to a further involvement of Italian regions to define a health planning that also includes chronic respiratory diseases (11-14).

Italy's health care system is a regionally based National Health Service [Servizio Sanitario Nazionale (SSN)] that provides universal coverage free of charge at the point of service. The system is organized into three levels: national, regional and local. The national level is responsible for ensuring the general objectives and fundamental principles of the national health care system.

Regional governments, through the regional health 


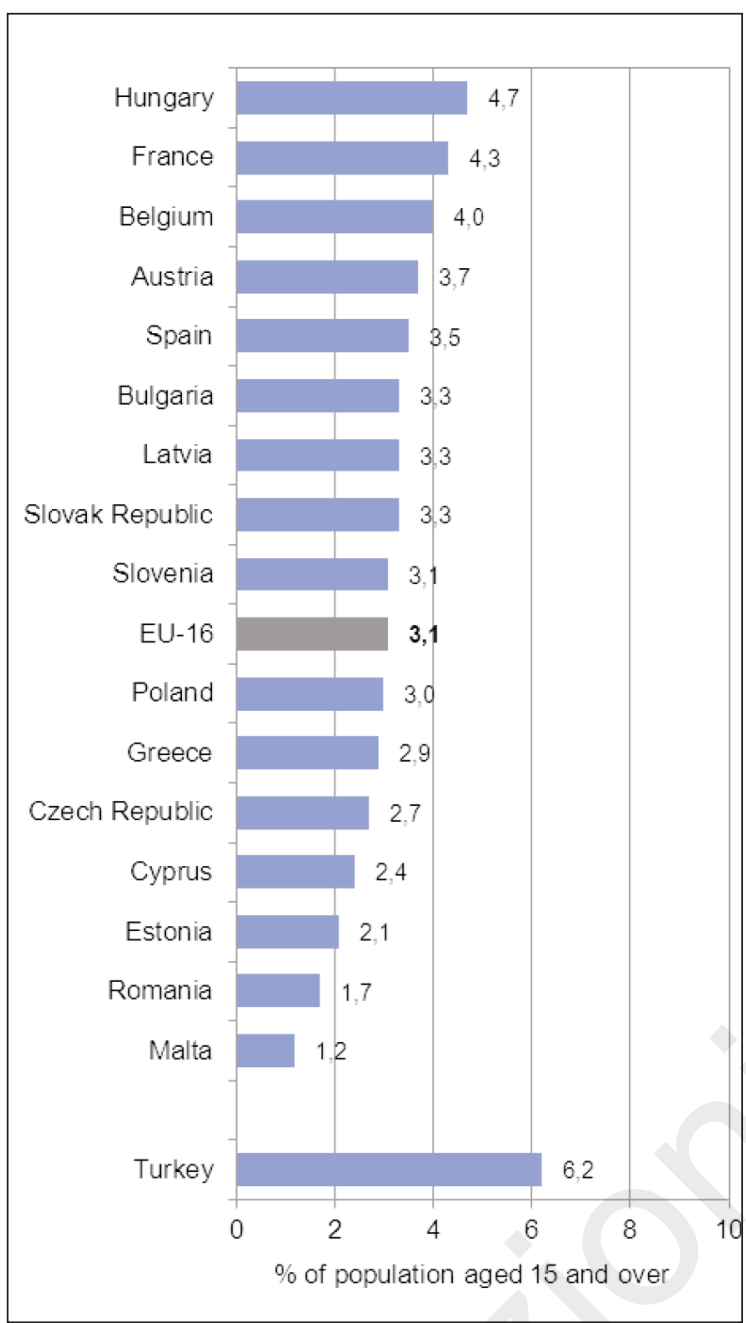

Figure 1 - COPD prevalence.

Self-reported COPD, 2008 (or nearest year)

Source: Eurostat Statistics Database.

OECD (2012), "Asthma and COPD prevalence", in Health at a Glance: Europe 2012, OECD Publishing.

http://dx.doi.org/10.1787/9789264183896-19-en.

departments, are responsible for ensuring the delivery of a benefits package through a network of populationbased ASLs - and public and private accredited hospitals (15).

COPD is a major mortality and hospitalization cause, especially in the elderly population (16). Elderly people are commonly affected by multiple diseases at the same time, consequently causing several management problems (17-19).

According to a study conducted by the Center for Social Investment (CENSIS) (20), in 2015 the Italian population over 65 years old will coincide with that of the young between 15 and 34 years old, i.e. about 12 and a half million people.

Demographic and epidemiological trends, medical treatment and changes in lifestyles have led to a gradual increase in chronicity.

Chronic obstructive pulmonary disease's model of care

Although the management of certain chronic diseases should be preferably dealt by mean of at home health services, it still relies on hospitals. Today a reorganization of responsibilities between hospitals and the territory is required to develop a new synergy, in which the former deals with the treatment of acute disease and the latter is responsible of the chronic aspect of the diseases themselves (21). The need for a care reorIntegrated care can be defined as a continuum of patientcentered services organized as a care delivery value chain for COPD patients with the goal of achieving the optimal daily functioning and health status for the individual patient and to achieve and maintain the individual's independence and functioning in the community. ganization deriving from a change in the social-epidemiological situation shall lead to the development of new care models.

The care models for chronic diseases shall emphasize the need to define systems that are well organized, integrated and proactive. The focus of these systems is the patient, who should be conscious of his situation and aware of his necessity to play a role in the management of his disease itself (22). The optimal treatment for COPD patients must address symptoms and disability from the respiratory disease and from its extra-pulmonary conditions, adhering to principles of the chronic care model and integrated care. Recently, the

American Thoracic Society de-

The patient should play a central role in the management of his/her own disease.

conditions with the goal of
achieving the optimal daily functioning and health status for the individual patient and to achieve and maintain the individual's independence and functioning in the community" (23).

The Chronic Care Model (CCM) is a care model for patients with chronic diseases that is based on six elements: the resources of the community, the health care organizations, support self-management, team organization, decision support and systems information (24).

The goal of the CCM is to deal with a conscious patient who interacts with a prepared and proactive team. The CCM has been introduced into the health systems intervention strategies of several countries, including Finland, Germany, the Netherlands and the United Kingdom.

In accordance with the system of the "community oriented primary care", the CCM was subsequently integrated with other aspects of the public health (Expanded Chronic Care Model- ECCM) $(25,26)$.

In Tuscany, the ECCM (Figure 2) has been adopted as the reference model (27).

According to the national guidelines, other Italian re- 


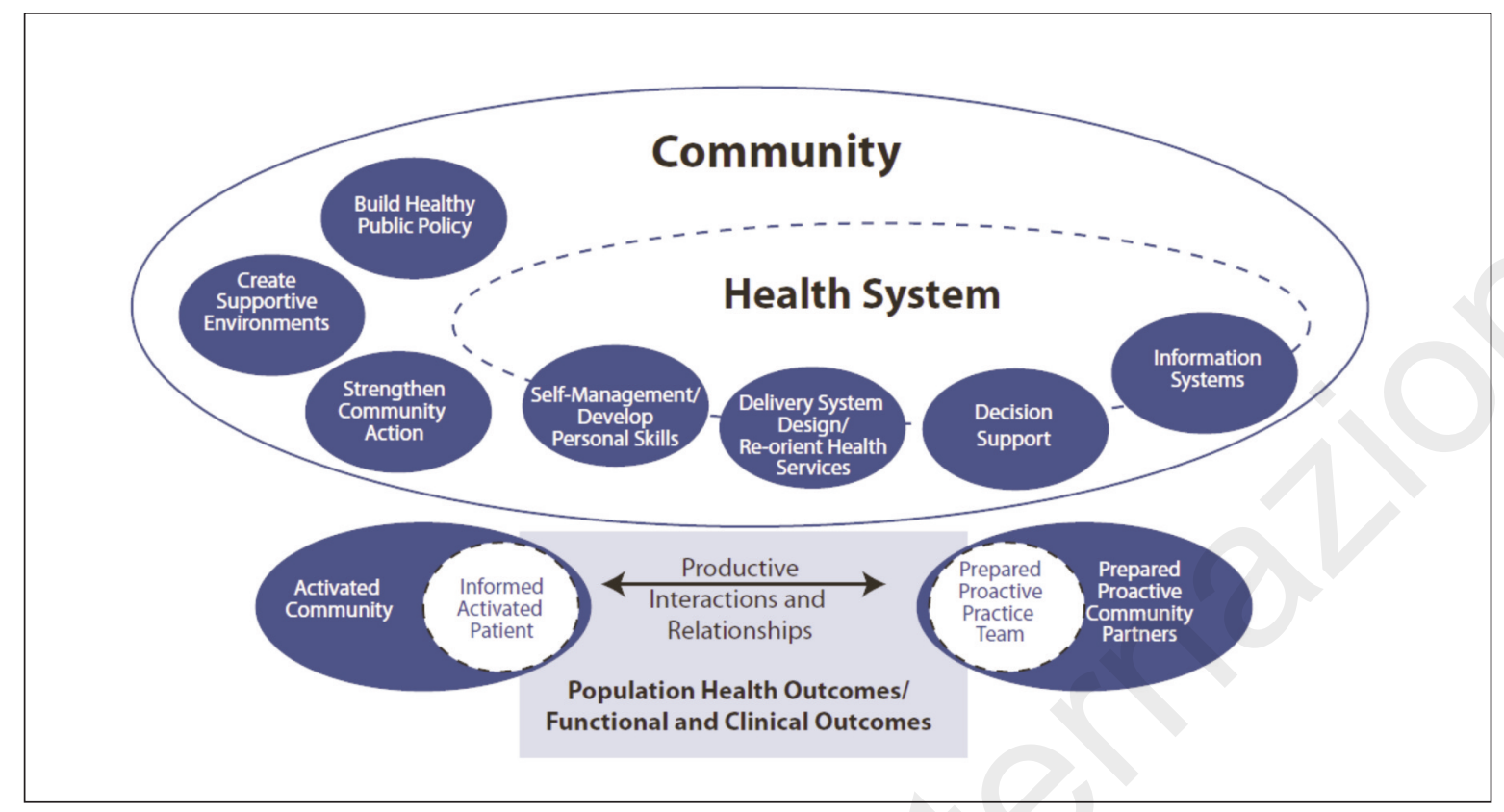

Figure 2 - Expanded Chronic Care Model (ECCM).

Created by: Victoria Barr, Sylvia Robinson, Brenda Marin-Link, Lisa Underhill, Anita Dotts \& Darlene Ravensdale (2002).

Adapted from Glasgow R, Orleans C, Wagner E, Curry S, Solberg L. (2001) "Does the Chronic Care Model serve also as a template for improving prevention?" The Milbank Quarterly, 79(4), and World Health Organization, Health and Welfare Canada and Canadian Public Health Association (1986). Ottawa Charter of Health Promotion.

gions have developed models for the proactive management of chronic diseases on local areas $(28,29)$. In addition to the CCM and to the ECMM, other models are the Kaiser Permanente's risk stratification model (30) and the patient-centered medical home (PCMH) (31). To date, the care models in Italy have a regional diversification, with some shared characteristics (32). COPD is an important component of chronic diseases

Pro-active primary
care for COPD can
reduce hospitaliza-
tions, but an optimal
chronic disease ma-
nagement requires a
high focus on main-
tenance.
and its care should therefore be placed within the programs already in place. It is important to act in a context of integrated management, according to a care process oriented to a shared management between the general practitioner - the patient's first reference, and the network of health professionals from local hospitals who are part of care delivery.

The role of the patient is also important: he must be conscious of his disease.

People affected by long term conditions should be involved in the development of a comprehensive set of self management tools. Moreover, the role of the patient's family and the world of volunteering are fundamental to create a complete management system, whose goal shall be an improved health together with an optimization of human and economic resources.
In this management scheme pulmonology plays a major role in specific phases of the disease.

Another model proposed for the organization of hospital pulmonology was also the Hub \& Spoke model, which expresses a care differentiation according to the degrees of complexity (33).

This operating model is consistent with the network approach of the hospitals and concentrates high specialized health services only in the main hospitals.

A recent act has indicated the minimum and maximum standards $(400,000-800,000$ people $)$ to size the hospital pneumological facilities (34).

Having different purposes from territorial assistance, this organizational structure specifically regards pulmonary care in hospital structures.

In a comprehensive system pneumological activity outside the hospital should be associated with the existing territorial care organizations and with the hospital care system.

Aiming to treat the root cause of the disease, proactive medicine offers the opportunity of maximizing the prevention (35). By doing this, proactive medicine differs from reactive medicine, which waits for the disease to appear and, consequently, rushes to resolve the symptoms.

As for many other chronic diseases, proactive and consistent primary care for COPD can reduce hospitalizations. It is important to note that optimal chronic disease management requires a high focus on maintenance. 
A recent document regarding COPD titled "integrated clinical management of COPD", created by the 3 major national scientific societies of respiratory medicine (AIMAR, AIPO and SIMeR), together with the Italian Society of General Medicine (SIMG), and in collaboration with the Ministry of Health and the National Agency for Health Services (AGE.NA.S), is an useful application tool for the integrated practice management of COPD care (36).

Integrated management requires the implementation of organizational models both at management and at professional level.

\section{Care delivery pathways}

In the Italian context the spread of integrated clinical practices, such as clinical or care pathways, is particularly important. In fact, the integrated clinical practices involve a major organizational change moving from a hierarchical management system, to a managerial system centered on processes.

The care delivery pathways are tools aimed at the implementation of the scientific guideline integrating two components: clinical recommendations from the $\mathrm{Na}-$ tional guidelines and specific adaption to the local context to facilitate their spread in the daily clinical practice (37).

The setting of the care pathway must take into account the entire care network in which a lack of coordination between structures at different levels is often present.

A consequence of this lack of coordination is the inappropriate use of hospitalization for chronic diseases that should find an adequate care setting over the territory (38).

An efficient system should seek its appropriateness both in terms of how clinical care activities are carried out, and where these actions can be completed in the best way.

A number of care pathways related to COPD have been successfully developed in Italian healthcare structures (39-42).

Furthermore, even specific regions have proposed integrated care pathways for COPD (43-45).

The design of a plan management system must consider the whole history of the disease, thus acting in line with the three levels of prevention.

In this context, the role of the respiratory specialist is pivotal, but it needs to be harmonized with the local model of primary care regarding chronic patients.

International guidelines and ongoing experiences highlight the need to work in multi-professional ways, using reference territorial structures (46).

The promotion of national reference documents by scientific societies of respiratory medicine is crucial (35), but a promotion of adaptation of the guidelines is also required in order to take into account the coexistence of several diseases in COPD patients (47).

The Italian Health System emphasizes the role of the regional level in planning, directing, controlling and coordinating the healthcare structures, so a particular attention should be paid to this level of government. In Italy, the regional level could represent an organizational structure in which different figures involved in COPD management care may be integrated.

In this way it may be easier to find a harmonization with either the existing care organization and the new models. Besides, the development of regional models of care pathways could also
The care delivery pathways are tools for the implementation of scientific guidelines integrating two components: the clinical recommendations of National guidelines and a specific adaption to the local context aimed to spread their application in the daily clinical practice. be a reference for the establishment of local care pathway. In this way, even through the development of common regional indicators, it would be possible to create useful benchmarking operations and to elaborate a strategy for care improvement.

The impossibility for all health structures to provide health care pathways according to the best practice, could represent the basis for developing new paths through inter-organizational models.

By sharing management processes aimed at improving interaction between healthcare structures located in a specific area, it is possible to get adequate specialist coverage in bordering areas lacking those structures.

An area with similar characteristics and a population of about 800,000 inhabitants (48) may represent the territory in which set up a project for the integrated COPD management.

Further, the possibility of having regional documents (44) referring to the establishment of local care pathway is then an opportunity to standardize as much as possible the care pathways.

In this context, the professional commitment of respiratory specialists must be directed at multiple levels. The technical cooperation should be present in both the pulmonary system of health planning, articulated in the national health plan and regional health plans, and in the local health planning.

In this perspective, national scientific societies of respiratory medicine should contribute with their national and regional representativeness to the definition of care pathways. These pathways must be integrated in a comprehensive hospital and territorial system able to guarantee the presence of a diffuse pulmonary specialist expertise.

\section{References}

1. Action plan of the Global Alliance against Chronic Respiratory diseases, 2008-2013. World Health Organization 2008.

2. Croxton TL, Weinmann, Senior RM, et al. Clinical research in COPD. Needs and Opportunities. NHLBI Workshop summary. Am J Respir Crit Care Med. 2003;167:1142-49. 
3. Buist AS, McBurnie MA, Vollmer WM, et al. BOLD Collaborative Research Group, International variation in the prevalence of COPD (the BOLD Study): a population-based prevalence study. Lancet. 2007; 370(9589):741-50.

4. Halbert RJ, Natoli JL, Gano A, et al. Global burden of COPD: Systematic review and meta-analysis. Eur Respir J. 2006;28:523-32.

5. Rycroft CE, Heyes A, Lanza L, Becker K. Epidemiology of chronic obstructive pulmonary disease: A literature review. Int $\mathrm{J}$ Chron Obstruct Pulmon Dis. 2012;7:457-94.

6. Cazzola M, Puxeddu E, Bettoncelli G, et al. The prevalence of asthma and COPD in Italy: A practicebased study. Respiratory Medicine. 2011;105:386-91.

7. Ministero della Salute. Piano sanitario nazionale 2006-2008.

8. Ministero della Salute. Piano nazionale della prevenzione 2010-2012.

9. http://www.who.int/respiratory/gard/en/ Consultato il 29.10.2013.

10. Elenco aderenti a GARD-I. http://www.salute.gov.it/ imgs/C_17_pagineAree_1605_listaFile_itemName_1_file.pdf. Consultato il 29.10.2013.

11. Regione Toscana. Piano Regionale della Prevenzione (PRP) 2010-2012.

12. Regione Siciliana. Assessorato alla Salute. Piano Regionale della Prevenzione 2010-2012.

13. Regione del Veneto. Piano Regionale Prevenzione anni 2010-2012.

14. Regione Marche. "Piano socio-sanitario regionale 2012/2014: "Sostenibilità, appropriatezza, innovazione e sviluppo".

15. Lo Scalzo A, Donatini A, Orzella L, et al. Italy: Health system review. Health Systems in Transition, 2009;11(6)1-216.

16. Fried LP, Ferrucci L, Darer J, et al. Untangling the concepts of disability, frailty, and comorbidity implications for improved targeting and care. J Gerontol. 2001;3:255-63.

17. Roland M, Paddison C. Better management of patients with multimorbidity. BMJ. 2013;346:f2510.

18. Guthrie B, Payne K, Alderson P, et al. Adapting clinical guidelines to take account of multimorbidity. BMJ. 2012;345:e6341.

19. Smith SM, Soubhi H, Fortin M, et al. Managing patients with multimorbidity: systematic review of interventions in primary care and community settings. BMJ. 2012; 345: e5205.

20. Ricerca «Gli anziani, una risorsa per il Paese», realizzata dal Censis per l'Anla (Associazione Nazionale Seniores d'Azienda), 2013.

21. Regione del Veneto. Piano socio-sanitario regionale (PSSR) 2012-2016.

22. Convegno Nazionale Agenas SANIT 2011 (Atti): I modelli organizzativi della medicina generale nella gestione delle patologie croniche: una proposta per l'analisi e la valutazione.

23. Nici L, ZuWallack R. An official American Thoracic Society workshop report: the integrated care of the COPD patient. Proc Am Thorac Soc. 2012;9:9-18.

24. Godlee F. Integrated care is what we all want. BMJ. 2012;344:e3959.

25. Coleman K, Austin BT, Bch C, Wagner EH. Evidence On The Chronic Care Model In The New Millennium. Health Affairs. 2009;28(1):75-85.

26. Barr VJ, Robinson S, Marin-Link B, et al. The expanded chronic care model: An integration of concepts and strategies from Population Health Promotion and the Chronic Care Model. Healthcare Quarterly. 2003;7:73-82.

27. Regione Toscana. Consiglio sanitario regionale parere n. 37 del 2008.

28. Ministero della Salute. Piano nazionale della prevenzione 2010-2012.

29. Ministero della Salute. Piano sanitario nazionale 2011-2013.

30. Making the NHS more like Kaiser Permanente. BMJ. 2004;328:763.

31. Berenson RA, Hammons T, Gans DN, Zuckerman S, Merrell K, Underwood WS, Williams AF. A House Is Not A Home: Keeping Patients At The Center Of Practice Redesign. Health Affairs. 2008;27(5):12191230.

32. Carbone C, Corsalini E, Longo F, Ricci A. Scenari per lo sviluppo dei servizi territoriali: confronto tra modelli regionali di presa in carico della cronicità. In Elena Cantù (a cura di), Rapporto OASI 2012, Milano, Egea, 2012.

33. Guzzanti E. L'ospedale del futuro: origini, evoluzione, prospettive. Rec Prog Med. 2006;97:594-603.

34. Legge n. 189/2012 "Conversione in legge, con modificazioni, del decreto-legge 13 settembre 2012, n. 158 , recante disposizioni urgenti per promuovere lo sviluppo del Paese mediante un più alto livello di tutela della salute".

35. Regione Toscana. Piano sanitario regionale 20082010 (punto 4.3 "Dalla medicina d'attesa alla sanità d'iniziativa").

36. La Gestione Clinica Integrata della BPCO. Edizione - ottobre 2013.

37. Cartabellotta A. Linee guida, percorsi, processi, procedure, protocolli. Il caos regna sovrano: è tempo di mettere ordine! GIMBEnews. 2008;1:4-5.

38. Noto G, Raschetti R, Maggini M. Gestione integrata e percorsi assistenziali. II Pensiero Scientifico Editore, 2011.

39. http://www.usl3.toscana.it/allegati/PROGETTO\%20C HRONIC\%20BPCO\%20con\%20schema_09122904 0616.pdf. Consultato il 5 novembre 2013.

40. http://www.asIromad.it/Allegati/RSPA_2012.pdf. Consultato il 5 novembre 2013.

41. http://www.asl.pavia.it/PDTA\%20BPCO $\% 20$ e\%20lnsufficienza\%20respiratoria\%20rev\%200\%202012.pd f. Consultato il 5 novembre 2013.

42. http://www.aslmi2.it/web/downloads.nsf/5E0D8B53B 6E83662862577D30075914D/\$FILE/PDTA_BPCO_ \%202012.pdf. Consultato il 5 novembre 2013.

43. Regione Liguria . Delibera di Giunta Regionale n. 518 del 4 maggio 2012 - Approvazione "protocollo per la gestione integrata delle patologie croniche epidemiologicamente più rilevanti (diabete, scompenso cardiocircolatorio, broncopneumopatia cronica ostruttiva)". 
44. Regione del Veneto. Proposta regionale di Percorso Diagnostico Terapeutico Assistenziale - PDTA per la BroncoPneumopatia Cronica Ostruttiva - BPCO. Vers. 9 ottobre 2013.

45. Regione Piemonte. Profilo Integrato di Cura della Broncopneumopatia Cronica Ostruttiva. Agenzia Regionale per i Servizi Sanitari. 2010.

46. Schede redatte dai tecnici regionali con indicazioni per la definizione del nuovo Patto per la Salute 2013 -2015. Aggiornamento 30 ottobre 2013.

47. Guthrie B, Payne K, Alderson P, McMurdo ME, Mercer SW. Adapting clinical guidelines to take account of multimorbidity. BMJ. 2012;345:e6341.

48. Regione del Veneto. DGR 3456 del 5 novembre 2004. Linee di indirizzo per la costituzione dell'area vasta. 